\title{
COMPARISON OF SCLEROTHERAPY BETWEEN SODIUM TETRADECYL SULPHATE AND 5\% PHENOL IN ALMOND OIL IN THE TREATMENT OF EARLY INTERNAL HAEMORRHOIDS
}

\author{
Debadatta Saha1, Pradip Sarkar ${ }^{2}$ \\ ${ }^{1}$ Senior Resident, Department of General Surgery, Agartala Government Medical College. \\ ${ }^{2}$ Associate Professor, Department of General Surgery, Agartala Government Medical College.
}

ABSTRACT

\section{BACKGROUND}

Sclerotherapy is a safe haemorrhoid treatment with minimum costs and side effects. Sclerotherapy is a time-honoured method and widely practised all over the world for the treatment of $1^{\text {st }}$ degree and $2^{\text {nd }}$ degree haemorrhoid by creating a fibrous reaction. We conducted this study to compare the efficacy and complication of sodium tetradecyl sulphate (STS) and 5\% phenol in almond oil using as an injection sclerotherapeutic agent in the treatment of early internal haemorrhoids.

\section{MATERIALS AND METHODS}

This is an open labelled, parallel group, single centred, hospital based randomised control study on 120 haemorrhoid cases visited in the department of surgery, AGMC \& GBP Hospital. Injection 3\% sodium tetradecyl sulphate has been given in the experimental group, and 1-3 mL (depending upon the size of the haemorrhoidal lesion) of the 5\% phenol in almond oil has been given in the control group. Patients were assessed 2 weeks thereafter. Data was analysed via SPSS-15 software. Chi-Square test and Logistic regression analysis were used to test for significance wherever necessary. $\mathrm{P}<0.05$ considered as a level of significance.

\section{RESULTS}

Out of 60 cases and 60 controls, 55.83\% were male. Commonest chief complaint was bleeding per rectum (83.33\%). The two groups were even regarding gender, age and chief complaint (P-value respectively 0.581, 0.615, 0.327). Bleeding after 2 weeks show a significant statistical difference between two groups ( $p$ value 0.038 ). Both sodium tetradecyl sulphate and phenol are having similar efficacy in controlling the prolapse, perianal itching and perianal discomfort ( $p$-value respectively $0.685,0.216,0.286$ ).

\section{CONCLUSION}

In an even sample sclerotherapy, phenol is having more efficacy than STS in controlling the bleeding per rectum. However, STS and phenol are having similar efficacy in controlling the prolapse, perianal itching and perianal discomfort.

\section{KEYWORDS}

Haemorrhoids, Sodium Tetradecyl Sulphate (STS), Phenol, Almond Oil, Sclerotherapy.

HOW TO CITE THIS ARTICLE: Saha D, Sarkar P.Comparison of sclerotherapy between sodium tetradecyl sulphate and 5\% phenol in almond oil in the treatment of early internal haemorrhoids. J. Evolution Med. Dent. Sci. 2016;5(100):7341-7343, DOI: $10.14260 /$ Jemds/2016/1662

\section{BACKGROUND}

Haemorrhoidal venous cushions are normal structures of the anorectum and are universally present unless a previous intervention has taken place. ${ }^{1}$ Internal haemorrhoids originate above the dentate line. External haemorrhoids occur below the dentate or pectinate line. ${ }^{2}$

Sclerosing agent blocks vessels and causes inflammation and fibrosis that fixes haemorrhoids to the surrounding tissue, preventing prolapsed. 3 The most common sclerosing agents used include $5 \%$ phenol in almond oil, ethanolamine oleate and sodium tetradecyl phosphate. 4,5 Other non-excisional procedures such as infrared coagulation or electronic probe coagulation have little proven advantage over injection

Financial or Other, Competing Interest: None.

Submission 23-10-2016, Peer Review 19-11-2016,

Acceptance 25-11-2016, Published 15-12-2016.

Corresponding Author:

Debadatta Saha,

Senior Resident

Department of General Surgery,

Agartala Government Medical College,

Agartala-799006,

Tripura (West), India.

E-mail: sahadebadatta@gmail.com

DOI: $10.14260 /$ jemds $/ 2016 / 1662$

\section{(c) $(i) \risingdotseq$}

therapy. ${ }^{6}$ Sodium tetradecyl sulphate commercially available as 1 or $3 \%$ solution in vials (Containing a total of 20 or $60 \mathrm{mg}$, respectively, in each 2 -mL vial). ${ }^{7}$

Sclerotherapy has proved to be useful for 1, 2, 3 grades of internal haemorrhoids lately. One to three $\mathrm{mL}$ of sclerosing agent is injected in the submucosa of each packet. ${ }^{8}$

Although many studies and research works have been done on the treatment of haemorrhoids, the number of literatures which compare the efficacy of the sclerosing agents in the treatment of early haemorrhoids is very less. To the best of our knowledge, there is no study available from this part of our country to compare the efficacy of sodium tetradecyl sulphate and 5\% phenol in almond oil for the management of early internal haemorrhoids.

\section{MATERIALS AND METHODS}

It is an open labelled, parallel group, single centred, hospital based randomised control study, conducted in the department of surgery, AGMC (Agartala Government Medical College) \& GBP Hospital. Allocation concealment done by sequentially numbered opaque sealed envelope. Patients divided into case and control groups by variable block randomisation. The procedure and data collection carried out for 18 months, from the month of January 2014 to June 2015. It has been carried 
out with prior approval from ethical committee of AGMC \& GBP Hospital, Agartala, Tripura.

A sample size of 120 patients of internal haemorrhoids ( 60 patients in each group) was sufficient to detect clinically important difference of $10 \%$ between groups in the continuance of bleeding at 14 days after sclerotherapy, using two sided Z-test of the differences between proportion with $80 \%$ power and $5 \%$ significance level.

After written consent, patients were examined with proctoscope. After the diagnosis has been confirmed, injection $3 \%$ sodium tetradecyl sulphate in experimental group and 1-3 $\mathrm{mL}$ of $5 \%$ phenol in almond oil in control group has been injected into the submucosa of each haemorrhoidal lesion. Patients were controlled 2 hours thereafter and assessed 2 weeks thereafter.

At the completion of this study, data entered in MS excel (move) for chart and analysed using SPSS15 software. ChiSquare test and Logistic regression analysis were used to test for significance. $\mathrm{P}<0.05$ will be considered as a level of significance.

\section{RESULTS AND ANALYSIS}

Out of 120 patients, 67 were males and 53 were females, constituting 55.83\% \& $44.17 \%$ respectively. Chief complaint was mostly bleeding per rectum (83.33\%). Demographic parameters were evenly set among patients as analysis confirms. Statistical tests reveal that groups are even regarding gender ( $p$-value 0.581), age ( $p$-value 0.616$)$, diet pattern ( $p$-value 0.408 ), socioeconomic status ( $p$-value 0.267 ), religion ( $p$-value 0.543 ), body habitus ( $p$-value 0.606 ), degree of haemorrhoids at presentation (p-value 0.130). Chief complaint was assessed and no difference was found between case and control group. P-values are 0.327, 0.130, 0.216, 0.286 for per rectal bleeding, prolapse of haemorrhoidal tissue, perianal itching and perianal discomfort respectively.

In the STS group, out of 48 patients who had per rectal bleeding at the time of presentation, 39 patients were not having any per rectal bleeding and 9 patients were still having per rectal bleeding, after 2 weeks of receiving injection sclerotherapy. In the phenol group, out of 52 patients who had per rectal bleeding at the time of presentation, 49 patients were not having any per rectal bleeding and 3 patients were still having per rectal bleeding, after 2 weeks of receiving injection sclerotherapy. The Chi-Square statistics is 3.9827 . The $\mathrm{p}$-value is 0.038978 . The result is significant at $\mathrm{p}<0.05$.

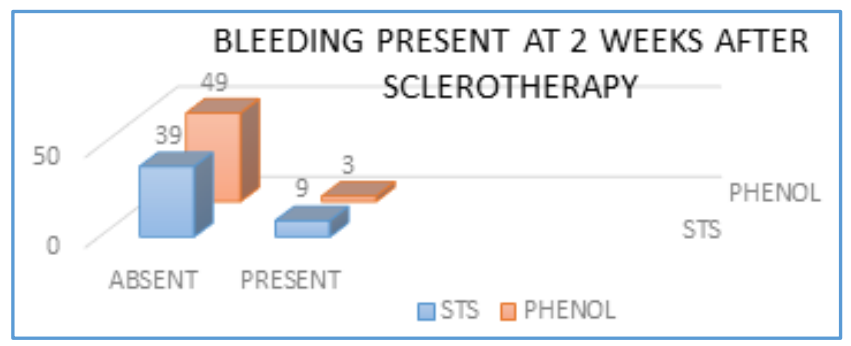

Figure 1. Bar Graph showing Bleeding Present at 2 Weeks after Sclerotherapy

\begin{tabular}{|c|c|c|c|}
\hline $\begin{array}{l}\text { Bleeding at Two } \\
\text { Weeks after } \\
\text { Sclerotherapy }\end{array}$ & $\begin{array}{c}\text { STS } \\
\text { Group } \\
(n=48)\end{array}$ & $\begin{array}{l}\text { Phenol } \\
\text { Group } \\
(n=52)\end{array}$ & P Value \\
\hline Absent & 39 & 49 & \multirow{3}{*}{$\frac{0.038978}{\text { therapy }}$} \\
\hline Present & 9 & 3 & \\
\hline Table 1. Bleedin & wo We & fter Sc & \\
\hline
\end{tabular}

Thus, our study shows that phenol is having more efficacy than STS in controlling the bleeding per rectum. Both STS and phenol are having similar efficacy in controlling the prolapse, perianal itching and perianal discomfort, p-values are 0.685 , 0.687 and 0.945 respectively.

Complications following the injection sclerotherapy are minimal, which are not serious and all these complications were treated by conservative measures. The development of complication following injection sclerotherapy among the STS group is not statistically different from the phenol group. The Chi-Square statistics is 4.5377 . The $p$-value is 0.208953 . The result is not significant at $\mathrm{p}<0.05$.

\section{CONCLUSION}

Sclerotherapy is a time-honoured method and widely practised all over the world for the treatment of $1^{\text {st }}$ degree and $2^{\text {nd }}$ degree haemorrhoid by creating a fibrous reaction. ${ }^{9}$

Outpatient treatment is widely acceptable and cost effective. There are many outpatient treatments amenable in the office like sclerotherapy, IR embolisation and rubber band ligation. The latter is more effective but has more pain postoperatively. $10,11,12$

Sclerotherapy has the least complications among other haemorrhoid treatments which prevents the progression of the disease.11,16 Sclerotherapy side effects are mostly urinary, frequently in anterior piles. So it is not recommended to use sclerotherapy in anterior haemorrhoids. ${ }^{13}$

Injection sclerotherapy is a relatively painless procedure which is less time consuming resulting in patient satisfaction. From the surgeon's point of view, it has less side effects, is fast and simple. High response rate in our series persuades us to use this simple, safe and now cost effective procedure in primary stages of the disease. Relying on the cultural situation of our society, we hope using nonsurgical treatments result in early presentation of the patients.

Phenol is having more efficacy than STS in controlling the bleeding per rectum. Both STS and phenol are having similar efficacy in controlling the prolapse, perianal itching and perianal discomfort.

The development of complications following injection sclerotherapy among both STS group and 5\% phenol group are not statistically different.

In this randomised controlled study, 120 patients of internal haemorrhoids (Grade I and grade II) were studied. The procedure and data collection has been carried out for 18 months, with effect from the month of January 2014 to June 2015. The conclusions drawn from this randomised controlled study of sodium tetradecyl sulphate and $5 \%$ phenol in almond oil using as an injection sclerotherapeutic agent in the treatment of early internal haemorrhoids are following:

1. Phenol is having more efficacy than STS in controlling the bleeding per rectum.

2. Both STS and phenol are having similar efficacy in controlling the prolapse, perianal itching and perianal discomfort. 
3. The development of complications following injection sclerotherapy among both STS group and $5 \%$ phenol group are not statistically different.

The present study was carried out over a period of only eighteen months and included a modest sample size of one hundred and twenty (120) subjects. Hence, factors such as seasonal variations, outbreaks of infectious diseases and a relative predominance of medical cases could have influenced this study. Other studies on larger scales over longer periods of time periods are required to properly validate the findings of this study. However, this study being the first of its kind from this part of country, will definitely help as a reference on which further larger studies could be conducted in future.

\section{Acknowledgements}

Hereby we should thank Agartala Government Medical College and GBP Hospital, who provided us the materials and resources for this study.

\section{REFERENCES}

1. Marx JA, Hockberger RS, Walls RM, et al, eds. Rosen's emergency medicine: concepts and clinical practice. $6^{\text {th }}$ edn. Philadelphia, PA: Elsevier 2006:1509-12.

2. Dayton, Lawrence PF, Bell R, et al. Essentials of general surgery. $4^{\text {th }}$ edn Philadelphia; Baltimore: Williams \& Wilkins 2006:p. 329.

3. Finkelmeier WR. Sclerotherapy. Chapter 12. In: Brennan ZF, Harken AH, Wilmore DW, eds. ACS surgery: principles \& practice. Web MD Inc 2004.

4. Quijano CE, Abalos E. Conservative management of symptomatic and/or complicated haemorrhoids in pregnancy and the puerperium. Cochrane Database of Syst Rev 2005;20(3):CD004077.
5. Akram Y, Tarar KD, Chaudhary ZA, et al. Role of sclerosing agents in the management of early haemorrhoids, a prospective comparative study comparing the results of sodium tetradecyl sulphate (STD 3\%) and phenol as sclerosing agents. Annals 2007;13(4):242-6.

6. Akerud L. Sclerotherapy of haemorrhoids: a prospective randomized trial of polidocanol and phenol in oil Coloproctology 1995;17:73-86.

7. Angio Dynamics Inc. Tetradecyl hydrogen sulfate (ester) injection solution prescribing information. Queensbury, NY 2008 .

8. Khazaei A, Sargazi-Moghadam M, Mazouchi M, et al. Comparison of hemorrhoid sclerotherapy using glucose $50 \%$ vs phenol in olive oil. Zahedan Journal of Research in Medical Sciences 2014;16(1):32-5.

9. Brunicardi FC, Andersen DK, Billiar TR, et al, eds. Schwartz's principles of surgery. $8^{\text {th }}$ edn. New York: McGraw-Hill 2005:1383-93.

10. MacRae HM, McLeod RS. Comparison of hemorrhoidal treatments: a meta-analysis. Can J Surg 1997;40(1):14-7.

11. Johanson JF, Rimm A. Optimal nonsurgical treatment of haemorrhoids: a comparative analysis of infrared coagulation, rubber band ligation, and injection sclerotherapy. Am J Gastroenterol 1992;87(11):1600-6.

12. Johanson JF, Sonnenberg A. The prevalence of haemorrhoids and chronic constipation. An epidemiologic study. Gastroenterology 1990;98(2):380-6.

13. Al-Ghaniem R, Leather AJ, Rennie JA. Survey of method of treatment of haemorrhoids and complications of injection sclerotherapy. Ann R Coll Surg Engl 2001;83(5):325-8. 